\title{
Erratum to: What Happens in the Lab Does Not Stay in the Lab: Applying Midstream Modulation to Enhance Critical Reflection in the Laboratory
}

\section{Daan Schuurbiers}

Published online: 13 December 2011

(C) Springer Science+Business Media B.V. 2011

\section{Erratum to: Sci Eng Ethics \\ DOI 10.1007/s11948-011-9317-8}

Unfortunately, Springer introduced two crucial mistakes in Dr D. Schuurbiers' article.

The correct title of the article is "What Happens in the Lab Does Not Stay in the Lab: Applying Midstream Modulation to Enhance Critical Reflection in the Laboratory".

The correct affiliation for Dr D. Schuurbiers is:

Centre for Society and Genomics, Radboud University Nijmegen, Nijmegen, The Netherlands

e-mail: schuurbiers@ society-genomics.nl

The online version of the original article can be found under doi:10.1007/s11948-011-9317-8.

D. Schuurbiers $(\bowtie)$

Centre for Society and Genomics, Radboud University Nijmegen, Nijmegen, The Netherlands e-mail: schuurbiers@society-genomics.nl 